\title{
Experimental Investigations on Fluoride Removal from Water Using Nanoalumina-Carbon Nanotubes Blend
}

\author{
K. Smitha, Santosh G. Thampi \\ Department of Civil Engineering, NIT Calicut, Kerala, India \\ Email: ksmitha.w@gmail.com
}

How to cite this paper: Smitha, K. and Thampi, S.G. (2017) Experimental Investigations on Fluoride Removal from Water Using Nanoalumina-Carbon Nanotubes Blend. Journal of Water Resource and Protection, 9, 760-769.

https://doi.org/10.4236/jwarp.2017.97050

Received: December 25, 2016

Accepted: June 10, 2017

Published: June 13, 2017

Copyright ( 92017 by authors and Scientific Research Publishing Inc. This work is licensed under the Creative Commons Attribution International License (CC BY 4.0).

http://creativecommons.org/licenses/by/4.0/

\section{cc) (i) Open Access}

\begin{abstract}
Fluoride is the most abundant, highly electronegative and geogenic contaminant in groundwater worldwide. Among the water quality parameters, the fluoride ion is unique in that it is beneficial to health if its concentration in water is within a threshold value $(1.0-1.5 \mathrm{mg} / \mathrm{l})$ and is detrimental $(>2 \mathrm{ppm})$ if present in excess (WHO, 2006). High fluoride levels in drinking water has become a critical health hazard of this century as it induces intense impact on human health including skeletal and dental fluorosis. The objective of this study was to evaluate the potential of nanoalumina-carbon nanotubes blend as a sorbent for the removal of excess fluoride from water. Batch studies were conducted to assess the influence of various operational parameters viz. $\mathrm{pH}$, temperature, agitation time, adsorbent dosage and presence of interfering ions. From the studies, it was clear that the rate of adsorption was initially rapid and attains equilibrium gradually in about $100 \mathrm{~min}$. The presence of interfering ions such as chlorides and sulphates has very little effect on fluoride removal by nanoalumina-carbon nanotubes blend. Analysis of the equilibrium data fitted the Langmuir and Freundlich isotherms very well. The results of the study appear to be quite promising in the sense that they demonstrate the capability of nanoalumina-carbon nanotubes blend for removing fluorides from drinking water.
\end{abstract}

\section{Keywords}

Adsorption, Carbon Nanotubes-Nanoalumina Blend, Batch Studies, Fluoride, Isotherm

\section{Introduction}

Water, an essential natural resource for sustaining life and the environment, is a 
free gift of nature [1]. Over the past few decades, increasing population, urbanization, industrialization and unscientific utilization of water resources have led to degradation of water quality in many parts of the world including India. Presence of various contaminants like fluoride, arsenic, sulphate, pesticides, heavy metals etc. in drinking water has been reported [2]. Among the water quality parameters, the fluoride ion is unique in that it is beneficial to health if its concentration in water is within a threshold value and is harmful if present in excess of that concentration [3]. Drinking water containing fluoride may be beneficial or detrimental to human health depending upon its concentration and total amount of fluoride consumed [4]. In view of the above, fluoride is often called a double-edged sword as deficiency in its intake has adverse health effects, viz. dental caries or tooth decay, while excess consumption leads to mottling of teeth in mild cases and fluorosis (dental or skeletal) and several neurological disorders in extreme cases [5]. According to the WHO guidelines, fluoride ion concentrations in above $1.5 \mathrm{mg} / \mathrm{l}$ in drinking water is harmful to human health [6].

High fluoride levels in groundwater and surface water in many parts of the world is a cause of great concern. Since fluoride is present in several naturally occurring minerals and geo-chemical deposits, and can be leached out by rainwater, it poses a threat of contaminating ground and surface waters [7]. Also, several fluoride containing compounds are extensively used in semiconductor and fertilizer industries and industries performing electrolysis of alumina, and these can contribute to fluoride pollution [8]. In India, fluorosis is prevalent in 17 states and it is quite severe in parts of Rajasthan (37 ppm), Gujarat (31 ppm) and Andhra Pradesh (20 ppm). Contrary to the general notion that the state of Kerala is richly endowed with fresh water resources, it is now widely recognized that the available resources are severely threatened by natural causes as well as anthropogenic activities. Excessive fluoride concentrations have been reported in recent times in some parts of Kerala as well $5.75 \mathrm{ppm}$ in groundwater at some locations in Palakkad district, Kerala [9]. Water with high fluoride concentrations has to be treated and made safe for human consumption before being supplied to the public.

Many methods have been reported for treating water with high fluoride concentrations such as adsorption, chemical treatment, ion exchange, electrodialysis, precipitation etc. [10]. Among these methods, adsorption is widely used for defluoridation [11]. The use of many materials including activated alumina, chemically activated carbon, fly ash, natural zeolites, bone charcoal, burnt clay etc. as adsorbents has been investigated. It is observed that large surface area and physicochemical interaction between the adsorbate and the adsorbent are important factors influencing fluoride adsorption from water. Alkaline $\mathrm{pH}$, large dosages of the adsorbent and low adsorption capacities limit the application of these materials.

Advances in nanoscale science and engineering suggest that many water quality problems could be resolved using nanosorbents, nanocatalysts etc. [12]. Nanomaterials are highly promising in applications involving water purification 
due to their unique properties like higher surface area per unit volume, ease with which they can be anchored onto solid matrices and their ability to functionalize with different groups, thereby enhancing their affinity towards target molecules [13]. Several studies on the use of nanoparticles for water purification have been reported [14].

In this study, an attempt is made to evaluate the performance of nanoalumina-carbon nanotubes blend in the removal of fluoride from drinking water. The influence of experimental parameters such as solution $\mathrm{pH}$, temperature, agitation time, adsorbent dosage and interfering ions on fluoride removal was investigated. Also, based on the experimental results, an appropriate adsorption isotherm model was identified.

\section{Materials and Methods}

\subsection{Materials}

Aluminium oxide nanoparticles and carbon nanotubes (CNTs) used in this study were procured from Sigma Aldrich Chemicals Pvt. Ltd, Bangalore, India. The size of nano aluminium oxide used in the study is less than $50 \mathrm{~nm}$ with surface area more than $40 \mathrm{~m}^{2} / \mathrm{g}$ and density $4 \mathrm{~g} / \mathrm{cc}$. Its melting and boiling points are $2040^{\circ} \mathrm{C}$ and $2980^{\circ} \mathrm{C}$ respectively. The length of the CNTs used is $0.1-10 \mu \mathrm{m}$, its outer and inner diameters are within the range $10-15 \mathrm{~nm}$ and $2-6 \mathrm{~nm}$ respectively and its density is $1.7-2.1 \mathrm{~g} / \mathrm{cc}$. A stock solution $(100 \mathrm{mg} / \mathrm{l})$ of fluoride was prepared by dissolving $221 \mathrm{mg}$ of anhydrous sodium fluoride (Merck, Germany) in one litre of distilled water. The working fluoride solution was prepared from the stock solution by appropriate dilution as outlined in the Standard Methods for Examination for Water and Wastewater (APHA, 1998).

\subsection{Methods}

Batch adsorption experiments were carried out at room temperature $\left(30^{\circ} \mathrm{C}\right)$ by placing $0.05 \mathrm{~g}$ nanoalumina-carbon nanotubes blend ( $\mathrm{NCB}$ ) in reagent flasks containing synthetic fluoride samples of initial concentration $20 \mathrm{mg} / \mathrm{l}$. The $\mathrm{pH}$ of the samples were varied from 2 to 10 . After the suspension $\mathrm{pH}$ was adjusted with $0.1 \mathrm{M}$ nitric acid or $0.1 \mathrm{M}$ sodium hydroxide solution, and was shaken in an ultrasonicator (Power Sonic, 405) for 1 hour, the suspension was filtered and the filtrate was analyzed for residual fluoride concentration. Measurement of fluoride ion concentration was performed using a $\mathrm{pH}$ meter (Orion, USA) equipped with a combination fluoride ion selective electrode. Fluoride concentration was measured according to the procedure described in the instrument manual. The fluoride ion selective electrode was calibrated prior to each experiment. Each test was conducted twice so as to obtain reproducible results with an error of less than $5 \%$. The amount of fluoride adsorbed onto the nanomaterials was determined from the difference between the initial and final concentrations of fluoride in the solution by following equation.

$$
q_{e}=\frac{\left(C_{i}-C_{e}\right) V}{W}
$$


where $q_{e}$ is the mass of fluoride adsorbed at equilibrium $(\mathrm{mg} / \mathrm{g}), C_{i}$ is the initial fluoride concentration $(\mathrm{mg} / \mathrm{l}), C_{e}$ is fluoride concentration at equilibrium $(\mathrm{mg} / \mathrm{l}), \mathrm{W}$ is the mass of adsorbent $(\mathrm{g})$ andV is the volume of solution (l).

To determine the influence of agitation time on fluoride removal, experiments were carried out at a $\mathrm{pH}$ of 7 , keeping the agitation speed constant at $150 \mathrm{rpm}$ and varying the agitation time. To study the influence of adsorbent dosage experiments were performed by changing the amount of adsorbent in the $100 \mathrm{ml}$ solution of sodium fluoride. The influence of temperature on fluoride adsorption was investigated by conducting experiments at different temperatures of solution $(298 \mathrm{~K}, 303 \mathrm{~K}, 308 \mathrm{~K}$ and $313 \mathrm{~K}$ ) keeping the fluoride concentration constant. Batch experiments were also conducted to study the presence of interfering ions in $0.01 \mathrm{M}$ salt solutions of chloride, sulphate, and bicarbonate separately at an initial fluoride concentration of $10 \mathrm{mg} / \mathrm{l}$, with a contact time $1 \mathrm{~h}$ and dosage $0.1 \mathrm{~g}$ of nanoalumina-carbon nanotubes blend.

\section{Results and Discussion}

\subsection{Characterization of Nano Alumina-CNTs Blend (NCB)}

Investigations were performed to assess the performance of nano alumina-CNTs blend (NCB) in adsorbing fluorides from water. Equal amounts of aluminium oxide nanoparticles and CNTs were mixed well. Then, distilled water was poured on to it and stirred well and thereafter the mixture was placed in a sonicator for one hour. Thereafter the material was filtered and dried. The morphological characteristics of the nano alumina-CNTs blend (NCB) used in this study were evaluated using a Hitachi SU6600 Variable Pressure Field Emission Scanning Electron Microscope (FESEM, Germany). Figure 1 shows the SEM image of NCB before and after adsorption. It can be observed from the images that, the adsorbent get agglomerated after adsorption.

\subsection{Influence of Experimental Parameters}

\subsubsection{Influence of $\mathrm{pH}$}

$\mathrm{pH}$ of the solution controls adsorption at the water-adsorbent interfaces. The optimal $\mathrm{pH}$ for adsorption of fluoride was determined by studying the uptake of
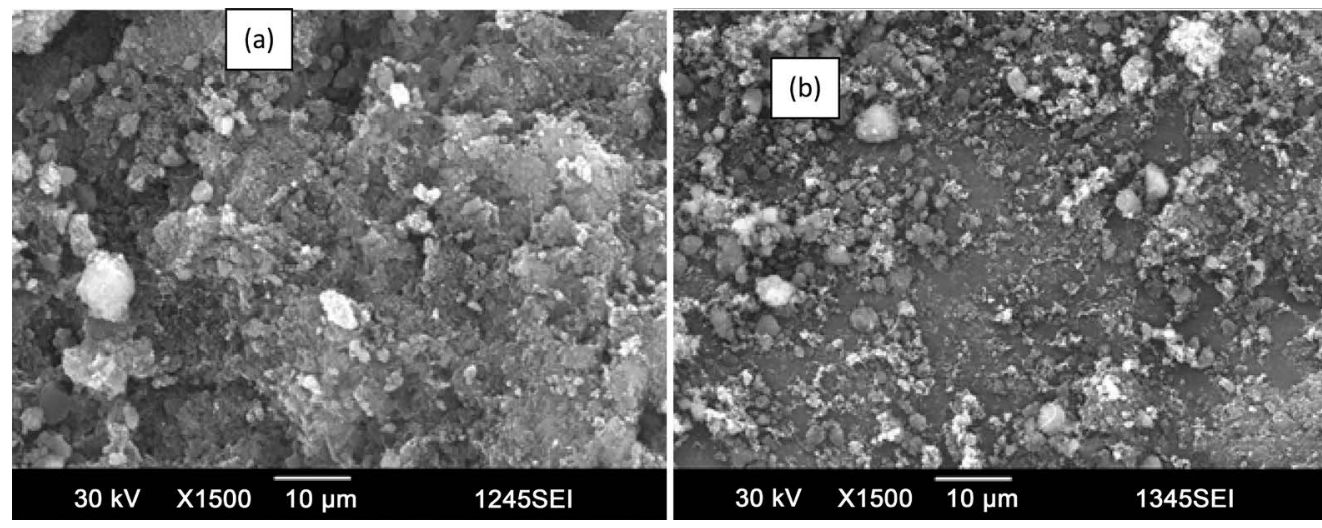

Figure 1. SEM image of NCB (a) before and (b) after adsorption. 


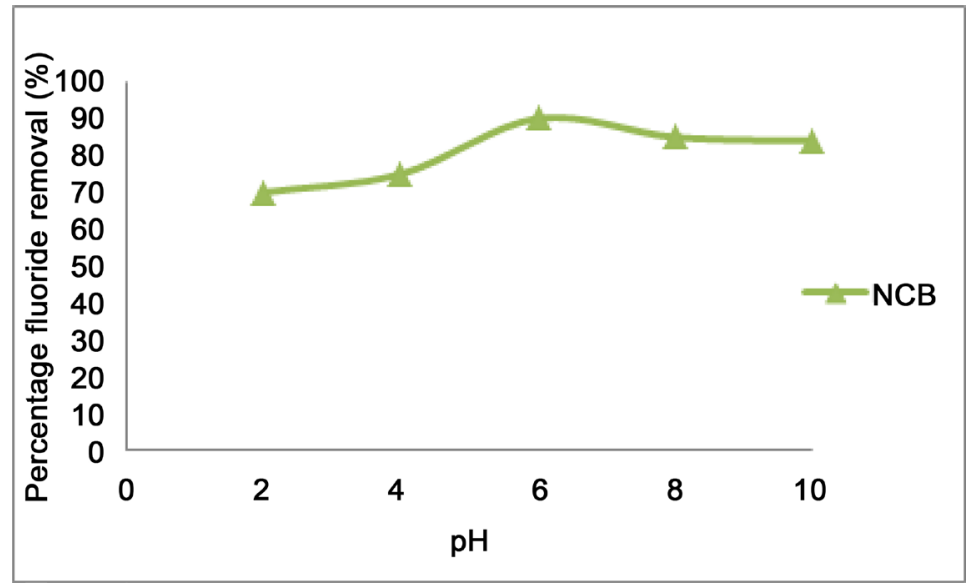

Figure 2. Influence of $\mathrm{pH}$ on the adsorption of fluorides.

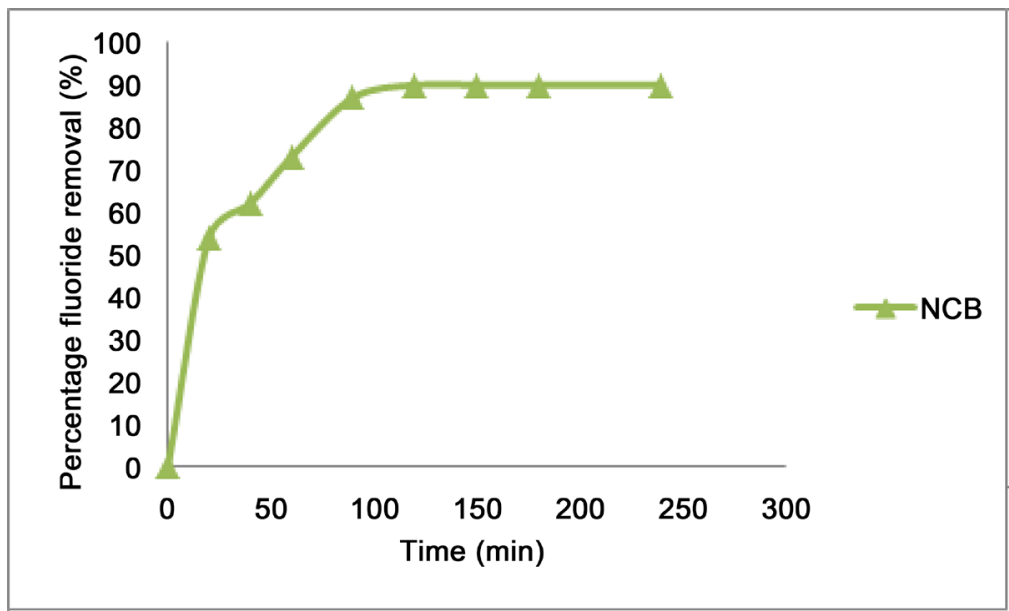

Figure 3. Influence of agitation time on the adsorption of fluorides.

fluoride using $\mathrm{NCB}$ at different $\mathrm{pH}$ values. It is evident from Figure 2 that these material exhibit high percentage removal over a $\mathrm{pH}$ range of $6-7$. The probable reason for the relatively lower fluoride removal in acidic range of $\mathrm{pH}$ is the formation of weakly ionized hydrofluoric acid which reduces the availability of free fluorides for adsorption. Similarly in highly alkaline conditions, low fluoride removal may be due to competition between $\mathrm{OH}^{-}$and $\mathrm{F}^{-}$ions for active sites on the material surfaces. Since maximum percentage removal was in the range of 6 to 7 , rests of the experiments were performed at a $\mathrm{pH} 7$.

\subsubsection{Influence of Agitation Time}

To determine the influence of agitation time on fluoride removal, experiments were carried out at a $\mathrm{pH}$ of 7 , keeping the agitation speed constant at $150 \mathrm{rpm}$ and varying the agitation time $(20 \mathrm{~min}, 40 \mathrm{~min}, 60 \mathrm{~min}, 90 \mathrm{~min}, 120 \mathrm{~min}, 150$ $\mathrm{min}, 180 \mathrm{~min}, 240 \mathrm{~min}, 300 \mathrm{~min}$ and $360 \mathrm{~min}$ ). The percentage of fluoride adsorbed increased with increase in agitation time (Figure 3 ) and attained an equilibrium at about $100 \mathrm{~min}$ for nanoalumina-carbon nanotubes blend (initial concentration $=20 \mathrm{mg} / \mathrm{l}$ at $30^{\circ} \mathrm{C}$ ). The same trend was observed at other temperatures also. The behavior observed may be due to reduction in the driving force 
after a long period of operation.

\subsubsection{Influence of Adsorbent Dosage}

Experiments were performed by varying the amount of adsorbent (adsorbent dosage) in the $100 \mathrm{ml}$ solution of sodium fluoride. The dosages adopted in this study were $0.02 \mathrm{~g}, 0.04 \mathrm{~g}, 0.06 \mathrm{~g}, 0.08 \mathrm{~g}, 0.1 \mathrm{~g}$ and $0.012 \mathrm{~g}$. It was observed from Figure 4 that the percentage removal of fluoride increased with increase in adsorbent dosage, all other factors being kept constant. As adsorption is directly based on the surface area available for sorption, for a fixed initial solute concentration, increasing the amount of adsorbent increases the surface area available for adsorption. Therefore more ions could attach to the surface of the adsorbents at higher adsorbent dosages.

\subsubsection{Influence of Temperature}

The influence of temperature on fluoride adsorption was investigated by conducting experiments at different temperatures of solution $(298 \mathrm{~K}, 303 \mathrm{~K}, 308 \mathrm{~K}$ and $313 \mathrm{~K}$ ) keeping the fluoride concentration constant. From the Figure 5 it can be seen that rise in solution temperature has an adverse effect on fluoride sorption by nanomaterials. This performance may be attributed to the fact that a

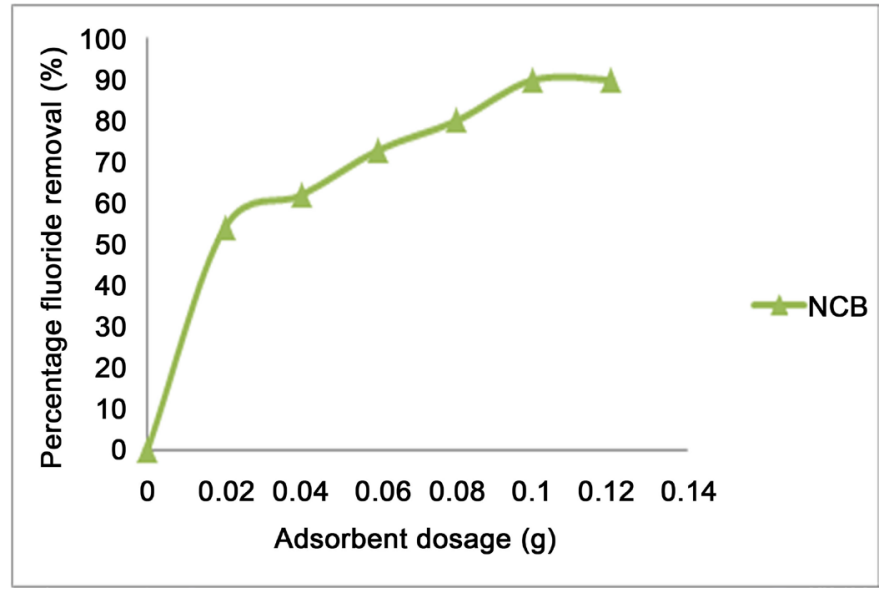

Figure 4. Influence of adsorbent dosage on fluoride removal.

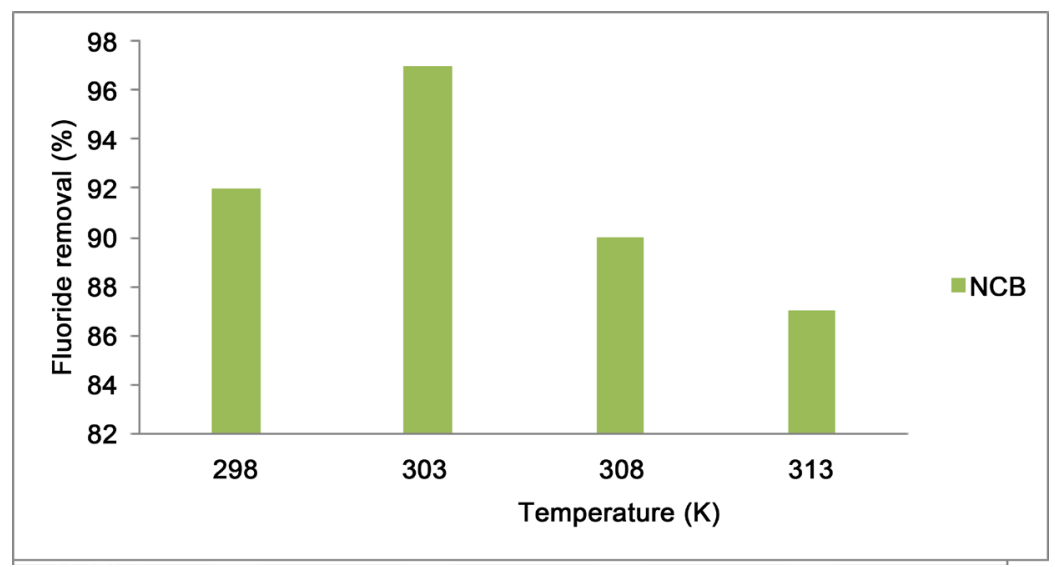

Figure 5. Influence of temperature on fluoride removal. 
rise in temperature increases the tendency of molecules of metals to escape from the interface, thereby diminishing the amount of sorption. Reduction in adsorption with increasing temperature indicates the exothermic nature of the adsorption process.

\subsubsection{Influence of Interfering Ions}

Contaminated ground water usually contains several ions coexisting with fluoride ions; these may compete with fluoride for active adsorption sites. Hence it is imperative to investigate the possible interference of these ions on fluoride adsorption by nanoparticles. The influence of coexisting anions such as sulphates, chlorides and bicarbonate on fluoride adsorption by nanoalumina-carbon nanotubes blend was examined and the results are presented in Figure 6. Batch experiments were conducted in the presence of $0.01 \mathrm{M}$ salt solutions of chloride, sulphate, and bicarbonate separately at an initial fluoride concentration of 10 $\mathrm{mg} / \mathrm{l}$, with a contact time $1 \mathrm{~h}$ and dosage $0.1 \mathrm{~g}$ of nanoalumina-carbon nanotubes blend. It was observed from the Figure 6, that the presence of interfering ions such as chlorides and sulphates has very little effect on fluoride removal using the blend nanoalumina-carbon nanotubes blend. The presence of bicarbonate ion showed higher inhibiting effect. This may be due to competition between the interfering ions and fluoride ions for active sites of nanomaterials. The order of interference with fluoride removal was

$$
\mathrm{HCO}_{3}^{-}>\mathrm{SO}_{4}^{2-}>\mathrm{Cl}^{-}
$$

\subsection{Modelling Equilibrium Sorption Using Langmuir and Freundlich Isotherms}

Analysis of adsorption data is important for predicting the adsorption capacity of a sorbent. The functional relationship between the amount of solute adsorbed per unit weight of the adsorbent and the concentration of adsorbate in bulk solution at a given temperature under equilibrium conditions is generally correlated by adsorption isotherms. Several equilibrium models have been developed and employed for such analyses. The two most commonly employed equilibrium

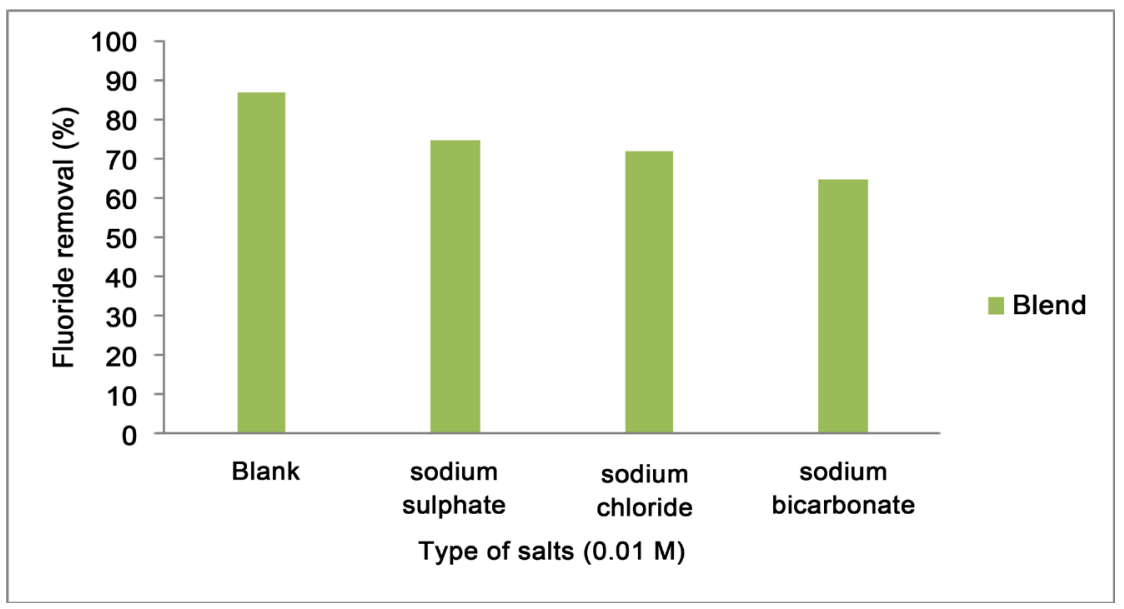

Figure 6. Influence of interfering ions in fluoride removal. 
models are the Langmuir and Freundlich equations. In the present investigation, an attempt was made to fit to both these isotherms.

The Freundlich adsorption isotherm generally fits experimental data over a wide range of concentrations. This empirical expression involves surface heterogeneity and the exponential distribution of active sites and their energies.

This isotherm can be expressed as

$$
q_{e}=K_{f} C_{e}^{1 / n}
$$

where $C_{e}$ in $\mathrm{mg} / \mathrm{l}$ and $q_{e}$ in $\mathrm{mg} / \mathrm{g}$ are the equilibrium concentration of metal ions in the liquid phase and in the solid phase respectively and $K_{f}$ and $n$ are the Freundlich coefficients. $K_{f}$ and $n$ are indicative of the adsorption capacity and intensity of adsorption.

The equation can be rewritten in linear form as

$$
\log q_{e}=\log K_{f}+\frac{1}{n} \log C_{e}
$$

The Freundlich constants $K_{f}$ and $n$ can be determined from the slope and y intercept of the linear plot of $\log q_{e}$ versus $\log C_{e}$. The estimated parameters for fluoride adsorption by nanoalumina-carbon nanotubes blend at $\mathrm{pH} 7$ using Freundlich isotherm models were given in Table 1.

In general, as the $K_{f}$ value increases, the adsorption capacity of the adsorbent increases. However, the Freundlich isotherm model, based on multilayer adsorption, described the data fairly well $\left(\mathrm{R}^{2}=0.99\right)$. The Freundlich adsorption constants $\left(K_{f}\right)$ obtained from the linear plot is 13.2. The Freundlich coefficient $(n)$, which should have values ranging from 1 to 10 , supports the favorable adsorption of fluoride onto the adsorbent.

Langmuir model was originally developed to represent chemisorption on a set of well-defined localized adsorption sites having the same adsorption energy, independent of surface coverage and with no interaction between adsorbed molecules. This model, also called the ideal localized monolayer model, is valid for monolayer sorption onto a surface with a finite number of identical sites.

In adsorption studies, applicability of the Langmuir isotherm suggests monolayer coverage of fluoride ions onto the surface of adsorbent. The Langmuir isotherm can be expressed as,

$$
\frac{C_{e}}{q_{e}}=\frac{1}{b q_{m}}+\left(\frac{1}{q_{m}}\right) C_{e}
$$

where, $b$ and $q_{m}$ are the Langmuir coefficients representing the adsorbate-adsorbent equilibrium and the monolayer capacity. A linear plot was obtained by plotting $\frac{C_{e}}{q_{e}}$ vs $C_{e}$ using the experimental data, from which the ad-

Table 1. Freundlich isotherm constants.

\begin{tabular}{cccc}
\hline Adsorbent & $\mathbf{R}^{2}$ & $K_{f} \quad(\mathrm{mg} / \mathrm{g})$ & $1 / n \quad(1 / \mathrm{mg})$ \\
\hline $\mathrm{NCB}$ & 0.99 & 13.2 & 0.35 \\
\hline
\end{tabular}


Table 2. Langumir isotherm constants.

\begin{tabular}{cccc}
\hline Adsorbents & $\mathbf{R}^{2}$ & $\mathbf{q}_{\mathrm{o}}(\mathrm{mg} / \mathrm{g})$ & $\mathbf{b}(\mathrm{l} / \mathrm{mg})$ \\
\hline NCB & 0.95 & 11 & 0.35 \\
\hline
\end{tabular}

sorption coefficients were evaluated. The constant $q_{m}$ signifies the adsorption capacity $(\mathrm{mg} / \mathrm{g})$ and $b$ is related to the energy of adsorption $(1 / \mathrm{mg})$. The estimated parameters for fluoride adsorption by carbon nanotubes-aluminium oxide nanoparticles blend at $\mathrm{pH} 7$ using Langmuir isotherm models were given in Table 2.

The adsorption capacity was found to be $11 \mathrm{mg} / \mathrm{g}$ and from the value of $\mathrm{R}^{2}$ it is clear that Freundlich isotherm is more fitted to this study. In order to determine whether the adsorption process is favourable or unfavourable, the isotherm shape was classified by the term dimensionless separation parameter $\left(R_{L}\right)$, which is defined as

$$
R_{L}=\frac{1}{1+b C_{0}}
$$

The value of $R_{L}$ indicates the feasibility of adsorption. $R_{L}$ value between 0 and 1 indicates favorable equilibrium and $R_{L}>1$ represents unfavourable equilibrium. In the present study the value of $R_{L}$ is obtained is less than one with all adsorbents which indicates a favourable adsorption process.

\section{Conclusion}

In this study, the suitability of carbon nanotubes-aluminium oxide nanoparticles blend for adsorbing fluoride ions from water was investigated. The influence of various parameters such as $\mathrm{pH}$, agitation time, adsorbent dosage and temperature on the adsorption process was determined by conducting a series of batch adsorption studies. The adsorption process performed better at $\mathrm{pH} 6-7$. Adsorption was exothermic and the rate of sorption decreased with increase in temperature. It is evident that a number of factors such as, $\mathrm{pH}$, contact period, adsorbent dosage, etc. play an important role in the adsorption process. Furthermore, these factors may interact with each other. Based on the results of this study, it can be concluded that carbon nanotubes-aluminium oxide nanoparticles blend is capable of removing fluorides from water. Langmuir and Freundlich models were used to predict the adsorption process. The Freundlich model fitted well to the experimental data on adsorption of fluoride. Chemisorption was found to be the dominant mechanism influencing adsorption of fluorides. The presence of interfering ions such as chlorides and sulphates has very little effect on fluoride removal. Bicarbonate ions inhibit the adsorption of fluoride from water to some extent. The study has demonstrated that the blend of carbon nanotubes-aluminium oxide nanoparticles (NCB) has more potential to remove fluorides from water.

\section{Acknowledgements}

I express my deep-felt gratitude to Kerala State Council for Science, Technology 
and Environment for funding this project.

\section{References}

[1] Sharma, S.K. (2003) High Fluoride in Groundwater Cripples Life in Parts of India. Diffuse Pollution Conference, Dublin.

[2] Meenakshi and Maheshwari, R.C. (2006) Fluoride in Drinking Water and Its Removal. Journal of Hazardous Materials, 137, 456-463.

[3] Ramanaiah, S.V., Venkatamohan, S., Rajkumar, B. and Sarma, P.N. (2006) Monitoring of Fluoride Concentration in Groundwater of Prakasham District in India: Correlation with Physico-Chemical Parameters. Journal of Environmental Science \& Engineering, 48, 129-134.

[4] Alagumuthu, G., Veeraputhiran, V. and Venkataraman, R. (2010) Adsorption Isotherms on Fluoride Removal: Batch Techniques. Archives of Applied Science Research, 2, 170-185.

[5] Gopalakrishnan, P., Vasan, R.S., Sarma, P.S., Ravindra Nair, K.S. and Hankappan, K.R. (1999) Prevalence of Dental Fluorosis and Associated Risk Factors in Alappuzha District, Kerala. National Medical Journal of India, 12, 99-103.

[6] WHO (2006) Fluoride in Drinking Water. IWA Publishing, London, 144.

[7] Tor, A. (2006) Removal of Fluoride from an Aqueous Solution by Using Montmorillonite. Desalination, 201, 267-276.

[8] Kagne, S., Jagtap, S., Thakare, D., Devotta, S. and Rayalu, S.S. (2009) Bleaching Powder: A Versatile Adsorbent for the Removal of Fluoride from Aqueous Solution. Desalination, 243, 22-31.

[9] Shaji, E., Bindu, Viju, J. and Thambi, D.S. (2007) High Fluoride in Groundwater of Palghat District, Kerala. Current Science, 92, 240-245.

[10] Ku, Y. and Chiou, H.-M. (2002) The Adsorption of Fluoride Ion from Aqueous Solution by Activated Alumina. Water, Air, and Soil Pollution, 133, 349-361. https://doi.org/10.1023/A:1012929900113

[11] Bhatnagara, A. (2011) Eva Kumara and Mika Sillanpaa, Fluoride Removal from Water by Adsorption-A Review. Chemical Engineering Journal, 171, 811-840.

[12] Savage, N. and Diallo, M.S. (2005) Nanomaterials and Water Purification: Opportunities and Challenges. Journal of Nanoparticle Research, 7, 331-342. https://doi.org/10.1007/s11051-005-7523-5

[13] Lisha, K.P., Anshup and Pradeep, T. (2009) Towards a Practical Solution for Removing Inorganic Mercury from Drinking Water Using Gold Nanoparticles. Gold Bulletin, 42, 144-152. https://doi.org/10.1007/BF03214924

[14] Li, Y.H., Zhao, Y.M., Hu, W.B., Ahmad, I., Zhu, Y.Q., Peng, X.J. and Luan, Z.K. (2007) Carbon Nanotubes-The Promising Adsorbent in Waste Water Treatment. Journal of Physics, 61, 698-702. 
Submit or recommend next manuscript to SCIRP and we will provide best service for you:

Accepting pre-submission inquiries through Email, Facebook, LinkedIn, Twitter, etc. A wide selection of journals (inclusive of 9 subjects, more than 200 journals)

Providing 24-hour high-quality service

User-friendly online submission system

Fair and swift peer-review system

Efficient typesetting and proofreading procedure

Display of the result of downloads and visits, as well as the number of cited articles Maximum dissemination of your research work

Submit your manuscript at: http://papersubmission.scirp.org/

Or contact jwarp@scirp.org 